Emmental and Simmental. Finally, we inspected Jura (or Freiberg) horses in the neighbourhood of Delémont, in the Bernese Juras. This is the only native Swiss breed; it is a light-draft type, developed during the last fifty years. Wherever we went we were warmly welcomed and most hospitably entertained.

The arrangements for the conference were excellent. It is all the more unfortunate that the currency restrictions which prevail at every frontier prevented many people attending the conference and reduced to a minimum the stay of many others. Voluminous literature was available about the Swiss breeds of livestock. More important, these books and brochures were not merely propaganda, but gave factual accounts of characteristics and performance of animals and of methods of breeding and herd book registration.

\section{INSULATING MATERIALS AND METHODS FOR USE AT LOW TEMPERATURES}

$\mathrm{T}$

HE Low Temperature Group of the Physical Society at a meeting on December 18, 1947, discussed insulating materials for use at low temperatures.

Sir Alfred Egerton, in the course of his presidential address to the Group, referred to the fact that the heat transfer by radiation in vacuum-jacketed vessels is greater than that predicted from theoretical calculations based on emissivities obtained from the electrical conductivities, and mentioned that a copper surface reduced with hydrogen at $300^{\circ} \mathrm{C}$. is a better reflector for heat waves than a polished surface.

Sir Alfred then described thermal conductivity determinations carried out under his and Prof. Newitt's direction by Dr. C. S. Chow at the Imperial College. The apparatus consisted of an inner cylinder maintained at low temperature by liquid oxygen and an outer cylinder which served both as a heater and a water flow-calorimeter; the material under test being packed between. Thermocouples were located at various positions to give the temperature distribution. Some of the data obtained are quoted below. They are mean thermal conductivities for a cold-face temperature of $-181^{\circ} \mathrm{C}$. and a mean temperature of about $-84^{\circ} \mathrm{C}$.

\begin{tabular}{|c|c|c|c|}
\hline Material & Description & $\begin{array}{c}\text { Bulk } \\
\text { density } \\
\text { (gm./c.c.) }\end{array}$ & $\begin{array}{l}\text { Thermal } \\
\text { conductivity } \\
\text { (gm. cal. cm./ } \\
\left.\mathrm{cm}^{2} \text { sec. }^{\circ} \mathrm{C} .\right)\end{array}$ \\
\hline $\begin{array}{l}\text { Granulated cork, } \\
\text { baked }\end{array}$ & $\begin{array}{l}49.5 \% \text { 10-20 mesh } \\
50.5 \% \text { through } 20 \\
\text { mesh }\end{array}$ & $0 \cdot 101$ & $0 \cdot 000066$ \\
\hline Vermiculite & $\begin{array}{r}10-14 \text { mesh } \\
\text { 4-10 mesh }\end{array}$ & $\begin{array}{l}0 \cdot 216 \\
0 \cdot 144\end{array}$ & $\begin{array}{l}0 \cdot 000112 \\
0 \cdot 000082\end{array}$ \\
\hline Mixed ," & $\left.\begin{array}{l}7 \cdot 9 \% 3-4 \text { mesh } \\
26 \cdot 5 \% \text { 4-10 }, \\
65 \cdot 6 \% 10-14,\end{array}\right\}$ & $0 \cdot 157$ & 0.000101 \\
\hline $\begin{array}{l}\text { Wadding } \\
\text { Slag wool }\end{array}$ & Crude cotton wool & $\begin{array}{l}0 \cdot 042 \\
0 \cdot 059 \\
0.130\end{array}$ & $\begin{array}{l}0.000062 \\
0.000076\end{array}$ \\
\hline ", ", & & $\begin{array}{l}0 \cdot 130 \\
0 \cdot 197\end{array}$ & $\begin{array}{l}0.000044 \\
0.000062\end{array}$ \\
\hline Cotton waste & $\begin{array}{l}\text { Tangled thread } \\
\text { form }\end{array}$ & $0 \cdot 131$ & $0 \cdot 000092$ \\
\hline
\end{tabular}

In a contribution from the National Physical Laboratory, Dr. Ezer Griffiths and Mr. M. J. Hickman reviewed the physical properties of insulating materials which have to be taken into account in practice in addition to thermal conductivity. They are bulk density, specific heat, fire resistance, water absorption, water repellency, permeability to water vapour, mechanical strength and settlement under vibration. The procedures for measuring these properties were outlined. For measuring thermal conductivity over the range of temperature of interest in refrigeration work, the hot-plate method was adopted: the plate being fitted with a coplanar guard ring. For the measurement of thermal conductivity down to about $-78^{\circ} \mathrm{C}$, a box or cylinder method has been used, the box being made of the material under test. The cold-face temperature was maintained at a constant low temperature by the use of a block of solid carbon dioxide, and the rate of sublimation of the solid carbon dioxide afforded a measure of the heat flow into the box.

A few of the results obtained with the various forms of apparatus are summarized below:

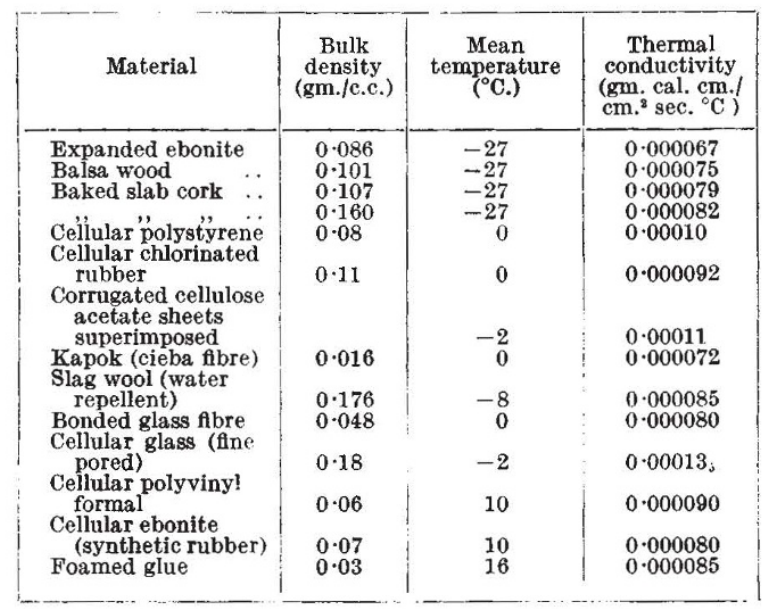

Dr. A. M. Clark (British Oxygen Co.) stated that the energy required to compensate the leakage of a unit of heat into a system at liquid oxygen temperature is fifteen to twenty times as great as that required to compensate for the leakage of the same quantity of heat at $-30^{\circ} \mathrm{C}$. The efficiency of a vacuum at liquid air temperature is about fourteen times that of a $10-\mathrm{cm}$. layer of a material such as baked slab cork. The complexity of the arrangement of a large industrial low-temperature plant, however, renders vacuum insulation impracticable to any great extent. He stated that the largest vacuum-insulated tank yet made for the storage of liquid oxygen had a capacity of 57 tons and an evaporation loss of 0.16 per cent of its contents per 24 hours. The largest storage vessel insulated with rock wool had an evaporation loss on the same basis of 0.2 per cent.

Sir Alfred Egerton stated that a vacuum-jacketed vessel of 30 gallons capacity for the storage of liquid methane had a rate of loss of $1 \frac{1}{2}$ gallons per 24 hours.

Dr. P. M. Schuftan (Gas Separation Branch, British Oxygen Co.) gave figures to show that the effect of improved insulation in oxygen plants was rather smaller than expected. For example, in an oxygen storage tank of $300,000 \mathrm{ft}^{3}$ capacity fitted with the usual magnesia insulation, about 3 per cent of the product is gasified by heat influx from outside. This amount of gas can, as a rule, be fully utilized for cylinder filling and only the latent heat of the oxygen is lost, adding about 2 per cent to power consumption and 1 per cent to total operating costs. 
Prof. F. E. Simon discussed the process of heat conduction in solids, emphasizing the role of the mean free path of the heat waves. Reduction of the mean free path by disturbing the lattice, either physically (mechanical distortion, use of supercooled disordered phases) or chemically (alloying), gave a very low thermal conductivity at low temperatures.

In the subsequent general discussion, stress was laid on the possibilities of an insulator composed of powder or fibres with gas at low pressures in the interspaces.

EZER GRIFFITHS

\section{SOME NEW ANISOTROPIC TIME EFFECTS IN RHEOLOGY}

\section{By S. M. FREEMAN and K. WEISSENBERG British Cotton Industry Research Association, Didsbury, Manchester}

\begin{abstract}
$\mathrm{N}$ rheology we study the development in space and Iime of the mechanical variables, that is, of the stresses and strains which co-exist in a material in every differential cell, and at every instant. Our concern here will be the comparison between different directions in space, and we shall speak with respect to any quantity, or development, of isotropic symmetry to denote identity in the various directions, and of anisotropic symmetry to denote differences from one direction to another.
\end{abstract}

Let a material be observed as it passes under some mechanical action through a series of rheological states, and let all such states be divided into sheared and shear-free states according as we can, or can not, find a tangential component of the mechanical variable under consideration on a plane of at least one orientation. It can then be shown that any passage between a shear-free and a sheared state will necessarily exhibit some anisotropic development in time, even if the material itself is of the isotropic kind, that is, shows the same response to mechanical actions in all directions of space when tested in a ground-state, where it is at rest and free from externally applied forces. (It follows from symmetry considerations that every shear-free state must be isotropic, and every sheared state anisotropic; and hence, any passage between the states of the two classes must exhibit anisotropic time effects with respect to the mechanical variable which possesses a tangential component.) We shall restrict our attention here to such isotropic materials, subjected to laminar shearing displacements. The laminæ which glide over one another will then suffer tangential and normal components of stress whichaccording to the theory ${ }^{1}$ - must vary simultaneously at differing percentage rates, showing, for example, different exponential indices during an exponential build up, or relaxation. In general, when the tan. gential component varies as an odd function of time, the normal one must simultaneously vary according to an even function, so that under vibrational displacements in which the former varies with some frequency around a mean value of zero and according to a sine function, the latter must vary simultaneously with double that frequency around a mean value different from zero, and according to a cosine function.

The experiments were actually made on isotropic materials of the visco-elastic type, such as liquid and solid colloids containing rubber, saponified oils, pastes

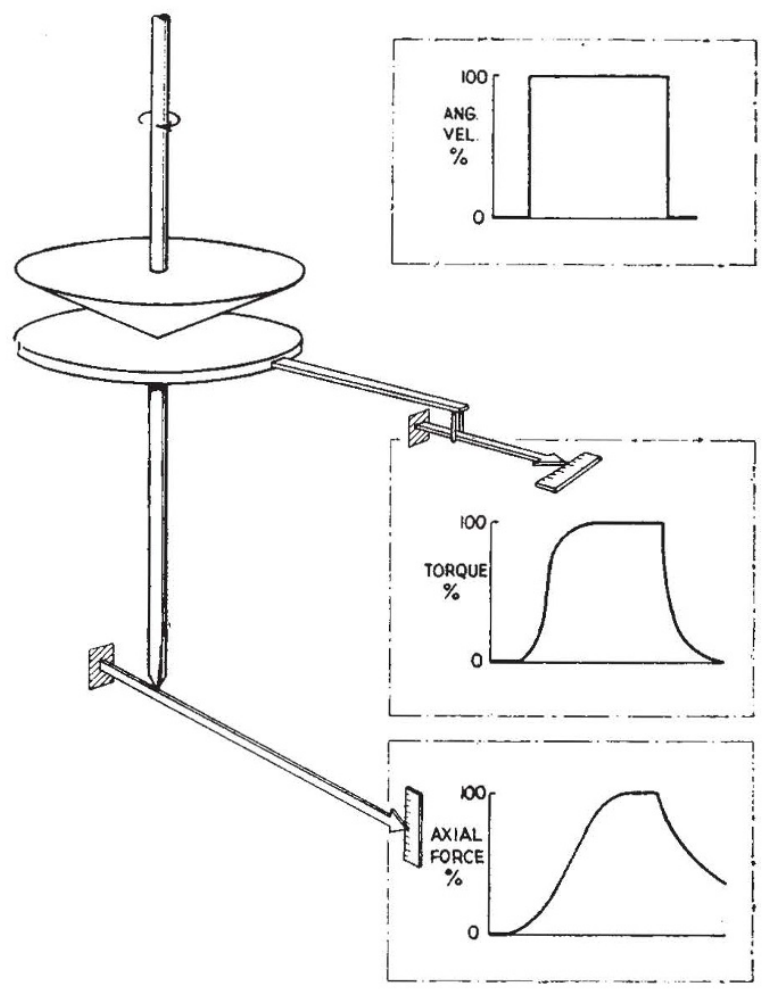

of starch, cellulose acetate, etc., because this type exhibits the anisotropic time effects in an easily accessible range of mechanical actions. (Liquids are understood here as materials which flow under any shearing stress, however small, while solids are capable of maintaining such stresses statically up to a certain limit.) Further, the materials were so selected as to be sensibly incompressible (within the range of applied actions), as this brings about a simplification of the effects here considered.

The accompanying illustration shows on the lefthand side a schematic diagram of the apparatus, and on the right-hand side a typical set of experimental results. The apparatus used was a version of the rheogoniometer ${ }^{2}$ specially designed to impose on a material laminar shearing displacements and to measure along various directions in space the development in time of the stresses. The framework of the apparatus consists of a watchmaker's precision lathe with its axis mounted in a vertical position. Concentric with this axis, and secured respectively in the head-and tail-stock of the lathe, are a circular cone (vertex downwards) and a plane circular disk, which touch one another, and form respectively the roof and the base of a horizontal gap of small height, containing the material under examination. One may impose on the material any laminar shearing displacement desired. For this the cone is rotated about its axis but held rigidly against axial translations, while the disk is kept sensibly at rest by constraints against both rotations and axial translations. The wedge-like shape of the gap then ensures that the material suffers the same amount of shear strain in every differential cell of the gap. The apparatus is equipped with measuring devices. For the strains the angle of rotation of the cone is measured and recorded as a function of time, while for the stresses it is necessary to register the action which the material 